\title{
Peran Guru Kelas dalam Meningkatkan Pemahaman Siswa pada Pembelajaran IPA Melalui Pembelajaran Berbasis Etnosains
}

\author{
Senjawati ${ }^{1}$ \\ ${ }^{1}$ Guru SDN 20/I Jembatan Mas, Jambi, Indonesia
}

\begin{tabular}{l} 
Article Info \\
\hline Article history: \\
Received Mei 3, 2020 \\
Revised Mei 22, 2020 \\
Accepted Mei 26, 2020 \\
\hline
\end{tabular}

\section{Keywords:}

Etnosains

Peran Guru

Pembelajaran IPA

\begin{abstract}
Tujuan penelitian: Guru merupakan tenaga pendidik yang prosfesional. Sebagai seorang tenaga yang profesional guru harus mampu menjadi fasilitator yang baik didalam kelas. Penelitian ini peran guru dalam meningkatkan pembelajaran IPA melalui pembelajaran berbasis Etnosains
\end{abstract}

Metodologi: Penelitian ini menggunakan metode eksperimen. Sumber data dalam penelitian ini yaitu kelas $5 \mathrm{~A}$ dan $5 \mathrm{~B}$ yang terdiri dari Kelas $5 \mathrm{~A}$ berjumlah 25 orang yang terdiri dari 10 laki-laki dan 15 orang perempuan. Sedangkan kelas 5B berjumlah 24 orang yang terdiri dari 12 orang laki-laki dan 12 orang perempuan

Temuan utama: Hasil dari penelitian ini menunjukkan bahwa terjadi peningkatan pemahan siswa pada materi organ pernapasan hewan dan fungsinyya secara signifikan pada kelas ekperimen setelah pembelajaran dilakukan berbasis Etnosains.

Keterbaruan penelitian: penelitian ini memiliki keterbaruan pada bidang pembelajaran yang efektif dan efisin menggunakan basis Etnosains pada pembelajaran IPA disekolag dasar.

This is an open access article under the $C C B Y-N C$ license

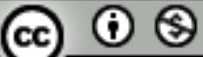

\section{Corresponding Author:}

Senjawati S.Pd

SDN 20/I Jembatan Mas, Batanghari

Email: senjawati@gmail.com

\section{PENDAHULUAN}

Pendidikan merupakan usaha sadar yang dilakukan manusia dalam meningkatkan kemampuan dan potensi diri yang dimilikinya. [1] Pendidikan adalah usaha sadar dan terencana untuk mewujudkan suasana belajar dan proses pembelajaran agar peserta didik secara aktif mengembangkan potensi dirinya untuk memiliki kekuatan spiritual keagamaan, pengendalian diri, kepribadian, kecerdasan, akhlak mulia, serta keterampilan yang diperlukan dirinya, masyarakat, bangsa dan negara. Artinya pendidikan memiliki peranan yang sangat penting bagi seorang manusia untuk tetap bertahan dan berkembang ditengah kemajuan zaman. Perkembang ilmu pengetahuan sangat berkaitan dengan hal-hal prinsip dalam kehidupan. [2] The development of science and technology has led to a process of change in all aspects of life, including the world of education. Secara sederhana pendidikan dilaksanakan di dalam lingkungan sekolah yaitu interaksi antara guru dan siswa.

Pembelajaran yang baik adalah pembelajaran yang berjalan secara aktif antara guru dan siswa. Guru berperan sebagai seorang fasilitator yang senantiasa membimbing seorang siswa. Pada proses ini, seorang guru harus memiliki kompetensi yang baik agar peran guru tersebut menjadi maksimal. [3] ada empat kompetensi yang harus dimiliki oleh seorang guru yaitu kompetensi pedagogik, profesional, kepribadian dan sosial. Seorang guru yang bisa disebut profesional dan berkompeten meliputi beberapa hal. 
[4] To be competent teachers, they need to accomplish three stages of teacher education and training, namely: 1) academic professional education; 2) professional education and training; 3) practical professional train. Guru profesional yang baik harus menguasai prinsip-prinsip pembelajaran misalnya rancangan pembelajaran dan penerapan model pembelajaran. [5] Professional teachers should ideally master a variety of learning models and can to apply them in accordance with prospective teacher conditions and learning objectives. Guru memiliki peranan yang sangat penting demi terciptanya pembelajaran yang baik. [6] One of the teachers has a position as a professional, as a professional, the teacher is required to have four compulsory competencies, namely pedagogic competence, professional competence, social competence, and emotional competence.

Pembelajaran IPA disekolah dasar dilaksanakan secara tematik. Pembelajaran IPA di sekolah dasar mengajarkan tentang mengenal konsep-konsep ilmiah yang dekat dengan alam sekitar seperti tumbuhan, hewan, manusia dan alam sekitar. [7] Pembelajaran Ilmu PengetahuanAlam (IPA) berkaitan dengan cara mencari tahu tentang alam secara sistematis. Guru harus mampu memfasilitasi siswa untuk paham tentang alam sekitar. [8] Pembelajaran IPA diharapkan bisa menjadi wahana bagi siswa untuk mempelajari diri sendiri dan alam sekitar, serta pengembangan lebih lanjut dalam penerapan dalam kehidupan sehari-hari. Dalam melaksanakan peran itu, guru dapat melakukan berbagai langkah. Salah satu yang dapat dilakukan yaitu melakukan pembelajaran berbasis etnosains.

Etnosains berkaitan erat antara bangsa atau kebudayaan dan sains atau IPA. [9] Etno (ethno) memiliki arti bangsa, sedangkan sains (science) artinya ialah pengetahuan. Etno sains dalam pembelajaran berkaitan dengan mengaitkan konsep-konsep IPA dalam kebudayaan suatu bangsa. [10] Ethnoscience is the knowledge that is indigenous to a particular language and culture. Artinya guru dapat mengaitkan antara konsep-konsep ilmiah dalam masyarakat ke dalam pembelajaran. Misalnya ketika membahas struktur tumbuhan maka guru mengenalkan tentang struktur tumbuhan endemik wilayah tersebut. Selain memudahkan siswa memahami konsep, pembelajaran dengan konsep etnosain akan menjadikan pembelajaran lebih dekat dengan siswa sendiri. Hal ini dapat diartikan pembelajaran IPA sangat efektif jika menggunakan konsep etno sains.

Penelitian ini bertujuan untuk mendeskripsikan peran guru dalam upaya meningkatkan pemahan siswa pada pembelajaran IPA berbasis etnosains disekolah dasar?

\section{METODE PENELITIAN}

Penelitian ini menggunakan Metode eksperimen dengan pendekatan kuantitatif. Penelitian ini dilaksankaan di SDN 20/I Jembatan Mas Kecamatan Pemayung Kabupaten Batanghari. Pada penelitian ini dilakukan dikelas 5 A dan 5B. Kelas 5A sebagai kelas eksperimen dan kelas 5B sebagai kelas kontrol. Pembelajaran dilaksanakan pada Sub Tema 1: Cara Tubuh Mengolah Udara Bersih, KD 3.2. Menjelaskan organ pernapasan dan fungsinya pada hewan dan manusia, serta cara memelihara kesehatan organ pernapasan manusia. Kelas 5A berjumlah 25 orang yang terdiri dari 10 laki-laki dan 15 orang perempuan. Sedangkan kelas $5 \mathrm{~B}$ berjumlah 24 orang yang terdiri dari 12 orang laki-laki dan 12 orang perempuan.

\section{HASIL DAN PEMBAHASAN}

Guru menjadi sosok penting demi terwujudnya pembelajaran yang baik. [11] Teacher performance is a success that will be achieved by a teacher in carrying out duties and responsibilities as a teacher in order to achieve the expected goals. Guru harus mampu menjadikan siswa menjadi bersemangat dalam pembelajaran sebab kepasifan siswa dalam pembelajaran akan berdampak pada keberhasilan belajar siswa. [12] Learners still tend to be passive, less critical and less creative during the learning activities. It affects the learning outcomes which are still under the Passing Grade (KKM). Pada pembelajaran IPA dikelas eksperimen dam kontrol dilakasankan secara proporsional baik kesamaan materi, waktu, media dan basis pembelajaran. Media pembelajaran sangat berguna dalam mebantu pembelajaran dikelas menjadi lebih efektif.

Pada materi menjelaskan organ pernapasan hewan serta fungsinya mendapatkan hasil pretes siswa dikelas eksperimen dengan nilai tertinggi sebesar 75 dan nilai terendah sebesar 40. Sementara dikelas kontrol mendapatkan hasil dengan nilai tertinggi sebesar 76 dan nilai terendah sebesar 48. Beberapa siswa belum mapu menjelas kan dan menjawab pertanyaan dengan sistematis dan terstruktur.

Tabel 1 Hasil Pretes kelas eksperimen dan kontrol

\begin{tabular}{cccc}
\hline \multirow{2}{*}{ No } & \multirow{2}{*}{ Hasil } & \multicolumn{3}{c}{ Kelas } \\
\cline { 3 - 4 } & & Eksperimen & Kontrol \\
\hline \multirow{2}{*}{1} & Skor tertinggi & 75 & 76 \\
\hline
\end{tabular}




\begin{tabular}{lcll}
\hline 2 & Skor terendah & 40 & 48 \\
3 & Rata-rata & 63 & 65 \\
\hline
\end{tabular}

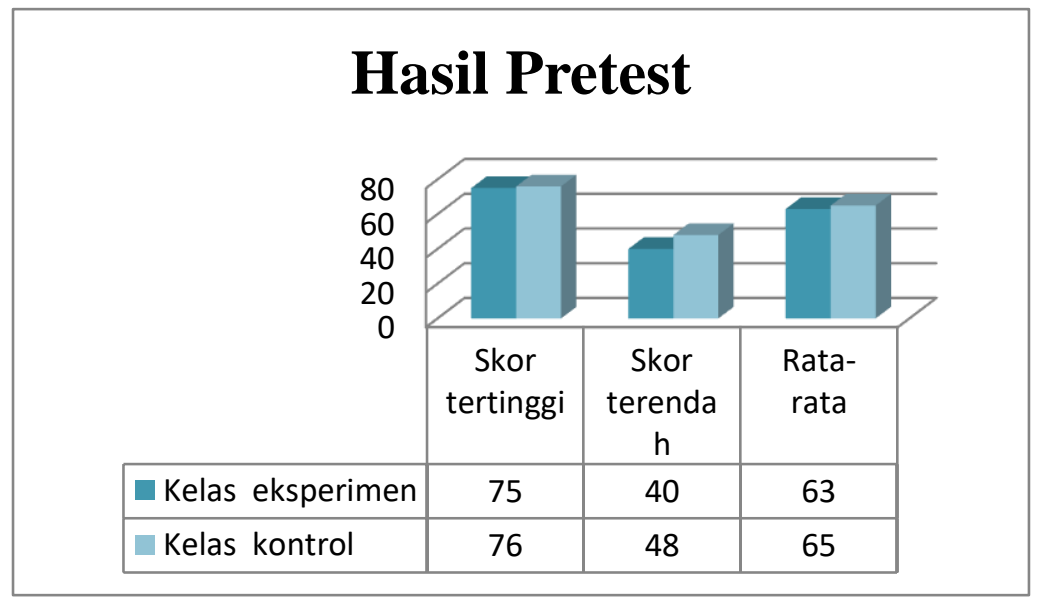

Gambar 1. Hasil Pretest

Pada pembelajaran pretest, pembelajaran dilaksanakan secara konvensional. Guru menejelaskan materi sesuai dengan buku panduan kemudian guru meminta siswa untuk menjawab pertanyaan yang berkaitan dengan organ pernapasan pada hewan. Siswa masih terlihat binggung pada saat menjawab pertanyaan tersebut. Siswa juga belum mampu menjelaskan tentang konsep pernapasan pada hewan. Selanjutnya pada postest siswa diberikan proses pembelajaran berbasis etnosains dan media pembelajaran berbasis etnosains. Berikut hasil postes setelah pembelajaran IPA dilakukan berbasis etnosains :

Tabel 2. Hasil Postest setelah diberikan perlakuan

\begin{tabular}{|c|c|c|c|}
\hline \multirow{2}{*}{ No } & \multirow{2}{*}{ Hasil } & \multicolumn{2}{|c|}{ Kelas } \\
\cline { 3 - 4 } & & eksperimen & kontrol \\
\hline $\mathbf{1}$ & Skor tertinggi & 90 & 82 \\
\hline $\mathbf{2}$ & Skor terendah & 82 & 75 \\
\hline $\mathbf{3}$ & Rata-rata & 86 & 77 \\
\hline
\end{tabular}

Berdasarkan tabel 2 diatas menunjukan bahwa pada hasil post tes terjadi peningkatan hasil pada kelas ekperimen skor tertinggi sebesar 90 dan nilai terendah sebesar 82. Sementara pada kelas kontrol juga terdapat kenaikan skor tertinggi sebesar 82 dan siswa yang mendapatkan skor terendah sebesar 75. Nilai ratarata yang didapatkan antara ke-2 kelas yaitu masing-masing sebesar 86 pada kelas eksperimen dan sebesar 77 pada kelas kontrol. Jika dibandingkan dengan pretest awal, sama-sama terdapat kenaikan perolehan nilai pada masing-masing kelas. Akan tetapi pada kelas eksperimen yang telah diberikan perlakuan terdapat kenaikan yang cukup signifikan. Dari pretest dengan skor 75 kemudian mendapatkan skor 90 pada postest.

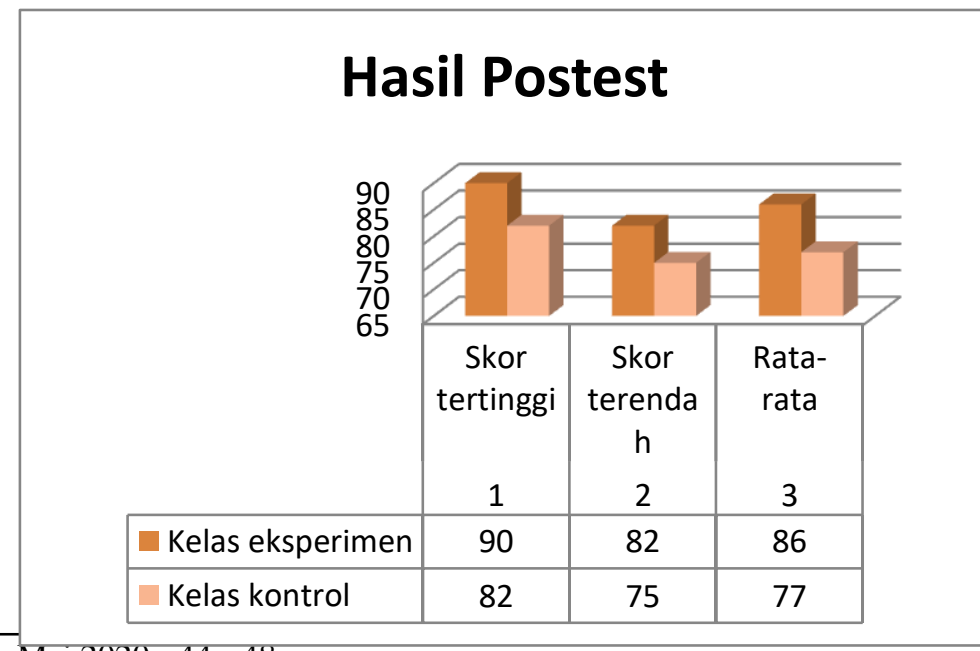


Gambar 2. Diagram Postest

Pada postest, siswa pada kelas eksperimen diberikan pembelajaran sengan basis etno sains. [13] Pembelajaran ilmu sains yang memperhatikan kearifan budaya lokal sebagai jatidiri bangsa dan, karakter dan adat istiadat budaya lokal dinamakan pembelajaran berpendekatan etnosains. Baik pada aspek soal maupun media pembelajarannya. Sementara pada kelas kontrol pembelajaran dilakukan secara konvensional. Siswa pada kelas eksperimen dijelaskan tentang macam-macam hewan asli sumatera yang juga terdapat di provinsi jambi misalnya harimau sumatra dan gajah sumatra. Selanjutnya siswa diminta untuk menjawab bagaimana cara harimau dan gajah sumatera bernapas seperti menggunakan paru-paru. Harimau dn gajah sumatera adalah hewan asli pulau sumatera yang tinggal di hutan tropis. Harimau dan gajah sumatera dapat ditemui di Taman Nasional Bukit Tiga Puluh (TNB30) yang berada diwilayah Kabupaten Tebo. Selanjutnya siswa diberikan gambar mengenai proses pernapasan hewan harimau sumatera. Siswa diminta untuk mengamati dan memberikan pertanyaan sesuai dengan gambar. Pembelajaran yang dekat dengan siswa mampu meningkatkan motivasi dan semangat siswa. Pembelajaran yang kontekstual juga dapat tercipta menggunakan basis etnosains tersebut. [14] Pembelajaran berbasis etnosains yang mampu menjembatani perpaduan antara budaya siswa dengan budaya ilmiah di sekolah akan mampu mewujudkan proses perkembangnya kualitas diri siswa. Kemampuan guru dalam merancang, melaksanakan dan mengevaluasi pembelajaran dengan baik menunjukan guru memiliki pengetahuan pedagogik yang baik pula. Pedagogical Knowledge (PK): PK relates to teaching methodologies and approaches, including knowledge in teaching and classroom management, assessment, evaluation, development of lesson plans (RPP), and student learning $[15,16]$.

Berdasarkan tabel 1 dan tabel 2, data tersebut menunjukan terjadi peningkatan setelah diberikan perlakuan pada setiap kelas. Siswa pada kelas eksperimen yang diberikan pembelajaran berbasis etnosains memiliki ketertarikan atau semangat belajar yang tinggi. Hal tersebut berdampak pada hasil penilaian yang naik secara signifikan. Sementara pada kelas kontrol terjadi kenaikan nilai tetapi tidak terlalu signifikan.

\section{KESIMPULAN}

Pembelajaran adalah sebuah proses yang dilakukan untuk mencapai sebuah tujuan dalam pendidikan. Pembelajaran sederhananya ada proses transfer informasi antara guru dengan siswa. Guru memiliki tugas dalam menjadikan siswanya sukses dalam proses pembelajaran. Kesuksesan belajar siswa dapat dilihat berdasarkan seberapa paham siswa terhadap hasil dari proses pembelajaran. Pembelajaran IPA berbasis Etnosains dapat meningkatkan pengetahuan siswa terhadap materi yang diajarkan guru dikelas. oleh karena itu guru harus senantiasa inovatif dalam menjalankan tugas dan kewajibannya.

\section{UCAPAN TERIMA KASIH}

Peneliti mengucapkan terimakasih kepada kepala SDN 20/I Jembatan Mas, Siswa dan siswi kelas 5 serta seluruh pihak yang mendukung sehingga penelitian ini dapat dilakukan dan menghasilkan sesuatu yang bermanfaat nantinya.

\section{REFERENSI}

[1] Undang-undang No 20 Tahun 2003 Tentang Sistem Pendidikan Nasional

[2] S. Syahrial., A. Asrial., D. A. Kurniawan., P. Nugroho., R. Septiasari., R. A. Pratama., \& R. Perdana. Increased Behavior of Students' Attitudes to Cultural Values Using the Inquiry Learning Model Assisted by Ethnoconstructivism. Journal of Educational Science and Technology (EST), vol. 5, no. 2, pp. 166, 2019. https://doi.org/10.26858/est.v5i2.9670. 2019

[3] Undang-undang No 14 Tahun 2005 Tentang Guru dan Dosen

[4] Soedijarto . Philosophical Foundation Of Teaching As A Profession And Its Implication On Teacher Education. International Journal of Education, vol. 5, no. 1, pp. 60-69. 2010.

[5] Asrial, Syahrial, D. A. Kurniawan., F. Chan., P. Nugroho., R. A. Pratama. \& R. Septiasari. Identification: The Effect Of Mathematical Competence On Pedagogic Competency Of Prospective Teacher, vol. 7, no. 4, pp. 9.2019

[6] Syahrial, Asrial, D. A. Kurniawan, F. Chan, A. Hariandi, R. A. Pratama, P. Nugroho \& R. Septiasari. The impact of etnocontructivism in social affairs on pedagogic competencies. International Journal of Evaluation and Research in Education (IJERE), vol 8, no. 3, pp 409-416. 2019.

[7] D. Kurniasih. Peningkatan Minat Dan Hasil Belajar Ipa Melalui Model Pembelajaran Think Pair Share. Natural: Jurnal Ilmiah Pendiidkan IPA, vol. 5, no.1, pp 7-11 2018. 
[8] P. R. I. Surahman., \& D. Tureni. Meningkatkan Hasil Belajar Siswa Dalam Pembelajaran IPA Pokok Bahasan Makhluk Hidup Dan Proses Kehidupan Melalui Media Gambar Kontekstual Pada Siswa Kelas II SD Alkhairaat Towera. Jurnal Kreatif Tadulako Online, vol. 3, no. 4, pp 91-107. 2014

[9] B. V. Nurdin. Kajian Antropologi Pariwisata Dan Ethno-Ecotourism Dalam Pengembangan Pariwisata Di Provinsi Lampung. Jurnal Kelitbangan, 04, pp. 120, 2015.

[10] O. S. Abonyi., L. Achimugu., Njoku, \& M. I. Adibe. Innovations in Science and Technology Education: A Case for Ethnoscience Based Science Classrooms. International Journal of Scientific \& Engineering Research, 5, 52, 2014.

[11] S. Pujiatuti., Murwatiningsih., \& R. Fahrur. The Influence of Professional Competence and Working Environment to The Teachers Performance of The Economic Teachers in Senior High School At Pemalang Regency Through Their Working Motivation. Journal of Economic Education, vol. 6, no. 2, pp.151-160. 2017.

[12] Taryadi \& Rusdarti. Problem-Based Learning Method Using Comic As A Medium Toward Students' Learning Outcomes Of Economy Social Science in Uang dan Lembaga Keuangan. Journal of Economic Educationn, vol. 7, no. 1, pp 1-9. 2018

[13] W. P. Hadi., \& M. Ahied. Kajian Etnosains Madura dalam Proses Produksi Garam sebagai Media Pembelajaran IPA Terpadu. Junal Ilmiah REKAYASA, vol. 10, no. 2, pp 78-86. 2017.

[14] I. Yuliana. Pembelajaran Berbasis Etnosains Dalam Mewujudkan Pendidikan Karakter Siswa Sekolah Dasar. Jurnal Pendidikan dan Pembelajaran Sekolah Dasar, vol. 1, no. 2, pp 98-106. 2017.

[15] A. Akmal. Local Culture And Morality Attachment To Tpack Framework Of Pre-Service English Teachers Within The Chalenge Of The 21st Century Skills. International Journal of Education, vol. 9, no. 2, pp. 113. 2014 https://doi.org/10.17509/ije.v9i2.5465

[16] F. Apriliyani. Identifikasi Motivasi Siswa Sekolah Dasar Menggunakan Video Animasi Tentang Sumber Daya Alam. Integrated Science Education Journal, vol. 1, no. 1, pp. 25-31. 2020 